\title{
A Case Study Perspective to the Digital Transformation of a Hospital's Perioperative Process
}

\author{
Jim Ryan \\ Auburn University at Montgomery \\ jryan@aum.edu \\ Sandra Daily \\ Princeton Baptist Medical Center \\ sandra.daily@bhsala.com
}

\author{
Barbara Doster \\ University of Alabama-Birmingham Hospital \\ bdoster@uabmc.edu \\ Carmen Lewis \\ Troy University \\ cclewis@troy.edu
}

\begin{abstract}
Based on a 177-month longitudinal study of a large 1,157 registered-bed academic medical center, this research examines the observed effects associated with the digital transformation of a United States hospital's perioperative process. The observed effects are viewed through a lens of information technology (IT) impact on core capabilities and core strategy to yield a digital transformation framework that supports patient-centric improvement across the perioperative sub-processes of pre-admissions, pre-operative, intra-operative, postoperative, and central sterile supply. This case study identifies existing perioperative sub-process limitations, potential capabilities, and subsequent sub-process contextual understanding to minimize perioperative process complexity. Specific perioperative nursing documentation as electronic medical records demonstrate the utility and value of patient-centric perioperative data collected within integrated hospital information systems as an organizational resource for process management and control. The case results are discussed, including theoretical and practical implications as well as study limitations.
\end{abstract}

\section{Introduction}

In 2009, the United States Congress passed the Health Information Technology for Economic and Clinical Health Act (HITECH) that authorized incentive payments through the Centers for Medicare \& Medicaid Services (CMS) to clinicians and hospitals to adopt and use electronic health records (EHRs) [9]. CMS's EHR Incentive Programs (CMSEHRIP) has quickened the digital transformation of healthcare delivery across the U.S. healthcare ecosystem in order to exploit the consensus that health information technology (IT) value propositions will improve healthcare quality and reduce costs [4]. Furthermore, the Joint Commission on Accreditation of Healthcare Organizations (TJC), and CMS require periodic performance and clinical outcome reporting as evidence of organizational quality, efficiency, and effectiveness. To meet these demands, administrators and medical professionals alike must leverage health IT to yield quality patient care, patient safety, process efficiencies, and cost effectiveness [32].
As of 2016, over 95\% of U.S. hospitals eligible for CMSEHRIP had achieved some level for meaningful use of certified EHRs [29]. CMS incentives accelerated the adoption rate of EHR technology among U.S. hospitals-up from only $7.6 \%$ in 2008 [21]. Likewise in 2016, U.S. healthcare spending accounted for $\$ 3.3$ trillion dollars with hospital care representing roughly one-third (\$1.08 trillion) of the dollars spent [11]. With CMS projecting U.S. healthcare spending to exceed $\$ 4.3$ trillion in 2021, the value propositions sought via digital transformation are essential to addressing increasing healthcare costs. However, successful digital transformation requires strategy on change management and application as well as technology implementation [17]. Hence, this research study focuses on understanding how to integrate and use health IT as these systems will have little impact on perioperative performance if they are not well integrated into daily workflows of healthcare providers $[4,48]$.

Within the hospital environment, patients and their care are the focus of work. Operationally, a hospital's perioperative process provides surgical care for inpatients and outpatients during preoperative, intraoperative, and immediate post-operative periods. Perioperative surgical care requires teams of multidisciplinary professionals, synchronously or asynchronously, to maneuver within complex, fastpaced, and critical situations - the hospital environment [26]. Accordingly, the perioperative process reflects patient flow, safety, and quality of care as well as stakeholders' satisfaction (e.g., patient, physician, nurse, perioperative staff, and hospital administration). Financially, the perioperative process is typically the primary source of hospital admissions, averaging between 55 to 65 percent of overall margins [30]. Earlier research shows 49 percent of total hospital costs are variable, with the largest category (i.e., 33\%) being the perioperative process [23]. To this end, health IT value propositions via digital transformation can yield perioperative quality improvement, efficiency, and cost effectiveness that ultimately affects hospital operational and financial performance.

This research investigates complexity and change dynamics during a hospital's perioperative process' digital transformation. The investigation method covers a longitudinal study of an integrated clinical scheduling 
IS (CSIS) implementation, integration, and use. The systematic analysis and subsequent contextual understanding during the perioperative digital transformation prescribed opportunity for measured improvement. Specifically, this research poses the research question as to what type of framework is applicable to promote a hospital's perioperative process' digital transformation that yields improved patient flow, integrated hospital IS to workflow coupling, and patient care accountability.

The following sections review previous literature with respect to digital transformation, business process management (BPM), key performance indicators (KPIs), and perioperative patient care. Following the literature review, we present our methodology, case study background, observed effects, and discussion. By identifying a holistic digital transformation framework that covers end-to-end perioperative sub-processes, this paper prescribes an a priori strategy for the occurrence. The conclusion also addresses study contributions, limitations, and implications.

\section{Literature Review}

Health IT capabilities in general and EHR (i.e., EMR) technologies in particular have the potential to fundamentally transform healthcare services [4]. However, the strategy as to how healthcare providers leverage and use the health IT capabilities will determine the level of digital business transformation success. Furthermore, Bhardawaj et al. [8] defines digital business strategy as how an organization applies and uses IT yielding a fusion between IT strategy and business strategy. Earlier in the literature, Applegate et al. [6] suggested organizations view their core capabilities and core strategy combined through an IT lens to delineate between IT impacts on core capabilities versus core strategy. The resulting IT Impact Map, denoted in Figure 1, illustrates the four modes an organization can exhibit by varying IT impact levels on core capabilities and core strategy.

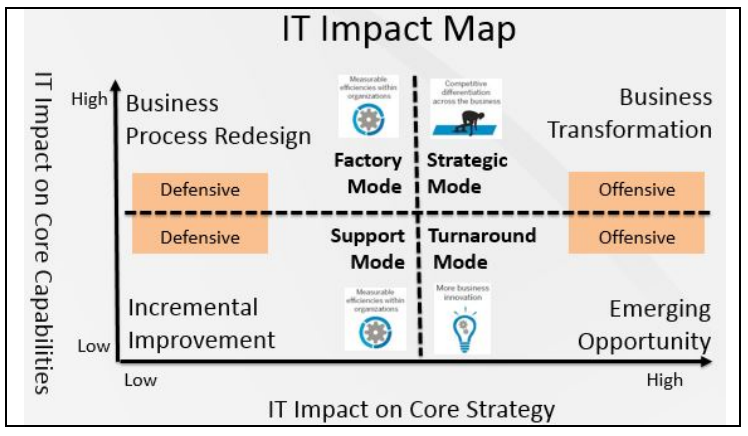

Figure 1 - IT Impact on Core Capabilities vs. Strategy

With respect to Figure-1 in a hospital environment, the two modes with low IT impact on core strategy represent defensive health IT applications with internal impact (i.e., measurable efficiencies) to the hospital. The two modes with high IT impact on core strategy represent offensive health IT applications with external impact (i.e., competitive differentiation) to the hospital. The following sections review literature on digital transformation, BPM, KPIs, and perioperative patient care as related to IT impact on core capabilities and core strategy.

\subsection{Digital Transformation}

Digital transformation is similar to the IT Impact Map's depiction of defensive and offensive IT impact. Digital transformation is evolutionary and leverages digital capabilities with emerging IT to enable business models, operational processes, and customer experiences to create value [27]. Re-phrased, digital transformation reflects the changes new IT makes in an organization's business model, which result in changed products or services, changed organizational structures, and/or the automation of business processes [17]. Moreover, the literature concurs that simply implementing or using IT is not enough to achieve digital transformation [5, 8, 17, 18, 21, 24, 27, 39, 40]. A key driver of digital transformation is the level of organizational digital maturity (e.g., higher is desired) found in the differences among organizational strategy, culture, and talent development [21]. Organizational culture, employee talent, as well as strategy all develop over time. Hence, digital transformation is evolutionary and organizations with higher digital maturity see more success through innovative IT implementation [21].

Forrester suggests digital transformation strategies focus on using IT to deliver internal operational excellence (i.e., defensive IT impact) and external customer experience (i.e., offensive IT impact) [40]. At the organizational level, digital transformation strategies have common dimensions where financial aspects must balance the use of IT, changes in value creation, and structural changes [24]. Digital transformation strategies also have cross-functional characteristics, which requires functional and operational strategy alignment or complex coordination efforts due to cutting across other strategies [24]. As an example at the patient level, the clinical use of IS and IT integration in acute critical care settings improves patient monitoring, bedside charting, and artificial support devices [34].

\subsection{Business Process Management (BPM)}

Continuous process improvement (CPI) is a systematic approach toward understanding process capability, customers' needs, and sources of observed variation. Tenner \& DeToro [42] views CPI as an organizational response to an acute crisis, a chronic problem, or an internal driver. CPI encourages bottomup communication in day-to-day operations (i.e., patient level) and requires process data comparisons to control metrics. Incremental improvement gains occur via 
iterative cycles of analysis, evaluation, and synthesis (i.e., plan-do-study-act) [46] to minimize observed variation. Doubt can exist as to whether: the incremental improvement addresses symptoms versus causes; the improvement effort is sustainable year after year; or management is in control of the process [19]. With respect to the IT Impact Map, the incremental improvement mode is invisible to external stakeholders.

Business process redesign (BPR) offers more radical redesign when compared to $\mathrm{CPI}$, with greater reward potential of upwards to 1,000 percent, while assuming the highest risk, durations, costs, and implementation difficulty [42]. BPR is the fundamental rethinking and radical redesign to achieve dramatic improvements in performance (e.g. cost, quality, service, and speed). BPR requires extensive resource allocations while seeking an order of magnitude improvement by questioning each activity’s relevance and reinventing new ways to accomplish necessary work. With respect to the IT Impact Map, the BPR mode has core business processes online in real-time, yet IT impact provides little strategic differentiation.

This study uses the BPM definition provided by Jeston and Nelis [19, p. 10] as "the achievement of an organization's objectives through the improvement, management, and control of essential business processes." The authors further elaborate that process management and analysis is integral to BPM, where there is no finish line for improvement. Hence, this study views BPM as an organizational commitment to consistent and iterative performance improvement that meets organizational objectives. Business analytics is the body of knowledge identified with technology solutions that incorporate definition and delivery of business metrics, performance dashboard management, as well as data visualization and data mining [44]. Business analytics within BPM focus on the effective use of organizational data and information to drive positive business action [39]. The effective use of business analytics demands knowledge and skills from subject matter experts and knowledge workers. Similarly, Wears and Berg [48] concur that IS and/or IT only yield high-quality healthcare when use patterns are tailored to knowledge workers and their environment. Therefore, BPM success has a strong dependence on stakeholders' understanding of core processes [19]. With respect to the IT Impact Map, BPM is applicable to either defensive or offensive health IT applications.

\subsection{Perioperative KPIs}

Performance measurement is essential for purposeful BPM, as information before and after the intervention is an integral part of process improvement. Early in the IT literature, Ackoff [1] proposed embedding feedback as control in IS design to avoid management misinformation. Similarly, organizations define data metrics as KPIs to monitor IS feedback of critical success factors (CSFs) [28, 33, 51] that reflect organizational action via business processes. Hence, the perioperative process is information intensive [10], partially due to perioperative process complexity [14].

Operational and tactical KPIs in perioperative subprocesses are numerous, but intra-operative KPIs should include: (1) monitoring the percentage of surgical cases that start on-time (OTS) or first-of-the-day surgical case on-time starts (FCOTS), (2) OR turn-around time (TAT) between cases, (3) OR utilization (UTIL), and (4) labor hours expended per patient care hour as units-of-service (UOS), [49, 16, 22, 30]. Tarantino [43] noted how OR TAT and a flexible work environment are CSFs for physician satisfaction, which in turn is a CSF for hospital margin. Poor KPIs on operational and tactical metrics (e.g., OTS, TAT, UTIL, or UOS,) affect strategic CSFs of patient safety, patient quality of care, surgeon/staff/patient satisfaction, and hospital margin $[25,30]$. With respect to the IT Impact Map, KPIs are applicable to measure performance in either defensive or offensive health IT applications.

\subsection{Perioperative Patient Care}

Specialized physicians (i.e. surgeons and anesthesiologists), nurses, and staff provide preoperative, intra-operative, and post-operative patient care. Hence, patient care occurs via perioperative teamwork at different times, at different locations, and with specific roles and activities that require awareness, communication, and coordination. Surgeons evaluate, prescribe, and perform the surgical procedure. Anesthesiologists evaluate, prescribe, and administer the induction-maintenance-emergence process of anesthesia [7]. Nurses evaluate, assist physicians, provide either ambulatory or acute care per physicians' instructions, as well as monitor and record all patient care activity. Perioperative staff facilitate location, supplies, instruments, and equipment per physician instructions. As a result, perioperative care yields end-state goals [41]: (1) a correct diagnosis for surgical intervention is identified with noted co-morbidities and patient consent; (2) a patient undergoes the surgical procedure; (3) a patient exhibits minimal exacerbation of existing disorders; (4) a patient avoids new morbidities; and (5) a patient experiences prompt procedure recovery. With respect to the IT Impact Map, defensive and/or offensive health IT applications are applicable to augment perioperative patient care and offer digital transformation opportunities.

\section{Research Method}

This research investigates the digital transformation of a hospital's perioperative process and questions the framework qualified to yield improved patient flow, integrated hospital IS to work coupling, and nursing care accountability. To this end, case research is particularly appropriate [13, 50]. An advantage of the positivist approach [47] to case research allows 
concentrating on a specific hospital service in a natural setting to analyze the associated qualitative problems and environmental complexity. Hence, our study took an in-depth case research approach.

Our research site (i.e., University Hospital) is an academic medical center, licensed for 1,157 beds and located in the southeastern region of the United States. University Hospital is a Level 1 Trauma Center, with a robotics program over eight surgical service specialties (SSS) as well as a Women's/Infant facility. University Hospital's recognition includes Magnet [2] since 2002 and a Top 100 Hospital by U.S. News and World Report since 2005. Concentrating on one research site facilitated the research investigation and allowed collection of longitudinal data. This research spans activities from August 2003 through May 2018, with particular historical data since 1993. During the 177month study, we conducted field research and collected data via multiple sources including interviews, field surveys, site observations, field notes, archival records, and document reviews.

\section{Case Study Background}

Perioperative Services (UHPS) is the University Hospital department designated to coordinate and manage perioperative patient care across Preadmissions, Admissions, Surgical Preparations (PreOP), Central Sterile Supply (CSS), Intra-operative and Endoscopy (OR), and Post Anesthesia Care Units (PACU). The workflow through CSS reprocesses all reusable surgical instruments/devices and transports supplies to and from PreOP, OR, and PACU areas. The following sections highlight tools, events, and outcomes that have shaped UHPS' BPM approach.

\subsection{CSIS implementation and new facility}

UHPS replaced its prior CSIS of 10 years in 2003. The new CSIS supports OLAP tools, a proprietary structured query language, and both operational and managerial data stores (i.e., an operational database and separate data mart). Flexible routing templates as surgical preference cards (SPCs) allow standardization of surgical care data (i.e., particular supplies and instruments) or SPC customization for specific surgeons and/or procedures. Since the 2003 CSIS implementation, over 7,750 generic and custom SPC configurations facilitate the surgical specialty services (SSS) represented in Table-1. Similarly, the CSIS data mart serves as the central repository for perioperative process data used to support improvement initiatives as well as report KPIs via a business intelligence layer for data visualization.

University Hospital opened a new diagnostic and surgical facility (i.e., North Pavilion) in November 2004. The new facility expanded UHPS' OR capacity by $33 \%$, providing state-of-the-art OR suites having standardized as well as surgical specific equipment.
Within six weeks of occupancy, a scheduling KPI reflected chaos. Surgical OTS plunged to $18 \%$ during December 2004. Having only 18\% OTS is unacceptable, as $82 \%$ of scheduled surgeries experience delays and risk patient care and safety.

Table-1 - University Hospital SSS

\begin{tabular}{|l|r|}
\hline Surgical Service Specialty (SSS) & SPCs \\
\hline BURN - Trauma burns & 26 \\
CARDIO - Cardiovascular \& Thoracic & 946 \\
ENT - Ear, Nose, \& Throat & $\mathbf{1 , 0 3 0}$ \\
GI - Gastro-intestinal & 460 \\
GYN - Obstetrics, oncology, incontinence & 611 \\
NEURO - Neurological & 763 \\
ORAL - Oral Maxil Facial & 236 \\
ORTHO - Orthopedic, joint/device & $\mathbf{1 , 2 0 8}$ \\
PLAS - Plastic surgery & 681 \\
SURG ONC - Surgical oncology & 329 \\
TX - Transplants (liver, renal) & 194 \\
TRAUMA - Trauma, MASH & 203 \\
URO - Urology & 533 \\
VASCULAR - arteries \& blood vessels & 558 \\
\hline
\end{tabular}

\subsection{Perioperative Process Improvement}

In January 2005, UHPS expressed concerns before a quickly convened meeting of c-level, nursing, and physician representatives. The meeting yielded a hybrid matrix-style management structure and governance in the formation of a multidisciplinary executive team, chartered and empowered to evoke change. The executive team consisted of perioperative stakeholders (e.g., surgeons, anesthesiologists, nurses, and UHPS), chartered to focus on patient care and safety, attack difficult questions, and remove inefficiencies. The resulting CPI effort addressed the perioperative crisis via numerous task forces employing data-driven evaluation of specific opportunities, which founded UHPS' current BPM approach [35].

Since 2005, UHPS has expanded its management beyond the initial general (GENOR) and cardio-vascular (CVOR) ORs within the North Pavilion campus to other campuses of the University Hospital Health System (UHHS) including OR suites at the Highland campus (HHOR) and Endoscopy (ENDO) labs at the TK Clinic campus. UHPS also developed a preoperative assessment, consultation, and treatment (PACT) clinic to manage all PreOP patient flow into UHPS. The PACT Clinic exists virtually in the CSIS, so the TK Clinic and HHOR allocated physical space for patient evaluations. Overall, UHHS has experienced a 10.9\% increase in surgical cases since 2007 with $59 \%$ of the average case volume being in-patient and $41 \%$ being out-patient. Emergency surgeries account for 5.3\% of the average case volume. Surgical case volume during FY2017 was 36,736 cases over the 58 ORs and 11 endoscopy labs. 
UHPS focuses BPM on data-driven analysis of KPIs at strategic, tactical, and operational levels via balanced scorecards and dashboards, aligned to hospital strategy [36, 38]. To this end, numerous BPM efforts have targeted multiple perioperative sub-processes to improve patient workflow [37]. Table 2 details a complete listing and timeline of BPM efforts as perioperative improvements by sub-process. All of the BPM efforts leveraged specific health IT applications to improve perioperative capabilities, with examples being: OR scheduling; hospital-wide electronic medical record (EMR) integration; preoperative patient evaluations; radio-frequency identification; and CSS/OR supply workflow.

Table 2 - Perioperative Improvements

\begin{tabular}{|c|c|c|}
\hline $\begin{array}{c}\text { Sub- } \\
\text { process }\end{array}$ & Improvement & Yr. \\
\hline All & Implemented the current CSIS & 2003 \\
\hline All & Relocated CSS and ORs & 2004 \\
\hline$\underline{\text { All }}$ & Governance change--initiated CPI & $\underline{2005}$ \\
\hline$\overline{\mathrm{OR}}$ & Initiated OR heuristic scheduling & 2006 \\
\hline All & $\begin{array}{l}\text { Addressed hospital-wide patient } \\
\text { flow (EMR, patient tracking, CPoE, } \\
\text { etc.) }\end{array}$ & 2007 \\
\hline All & $\begin{array}{l}\text { Established KPI reporting } \\
\text { (strategic, tactical, and operational) }\end{array}$ & 2008 \\
\hline All & AMC21 Balanced Scorecards & 2010 \\
\hline PreOP & Developed PACT Clinic & 2011 \\
\hline OR & RFID phased implementation & 2012 \\
\hline $\begin{array}{l}\text { CSS \& } \\
\text { OR }\end{array}$ & $\begin{array}{l}\text { Redesigned supply workflow } \\
\text { (CSS-to-OR-to-CSS) }\end{array}$ & 2013 \\
\hline All & $\begin{array}{l}\text { Unit-of-service CSIS charge via } \\
\text { EMRs }\end{array}$ & 2014 \\
\hline $\begin{array}{l}\text { CSS \& } \\
\text { OR }\end{array}$ & $\begin{array}{l}\text { Instrument reprocessing \& tracking } \\
\text { (CSS-to-OR-to-CSS) }\end{array}$ & 2015 \\
\hline All & $\begin{array}{l}\text { Real-time perioperative KPIs \& } \\
\text { dashboards }\end{array}$ & 2016 \\
\hline All & Automated EMR Reconciliation & 2017 \\
\hline
\end{tabular}

\subsection{Patient flow and integrated hospital IS}

Surgical patient admissions occur via the PACT Clinic, with referrals via three venues: 1) diagnostic office visits to physicians within the TK Clinic, 2) nonUHHS physicians, or 3) the Emergency Department. All surgical patients receive a PACT Clinic evaluation prior to their scheduled procedures. Figure-2 depicts the integrated hospital IS used to facilitate and document perioperative patient care across UHHS. All UHHS patients' (i.e., in-patient or outpatient) medical records, admissions, diagnostics, clinical data and observations, as well as discharges are processed and recorded via the same integrated hospital IS. All IS depicted in Figure-2 are integrated with either uni-directional constraints for limited data exchange or bi-directional data exchange.
The seven IS clustered around the CSIS are modules that directly support and extend the CSIS suite, where the Clinical Charting IS houses CPoE and EMRs. The HIPPA compliant Web services and BMDIB integrate ancillary IS, clinical data sensors, and bio-medical equipment. The institutional intranet serves as single entry portal access to extend each IS according to particular user-IS rights and privileges negotiated via user authentication.

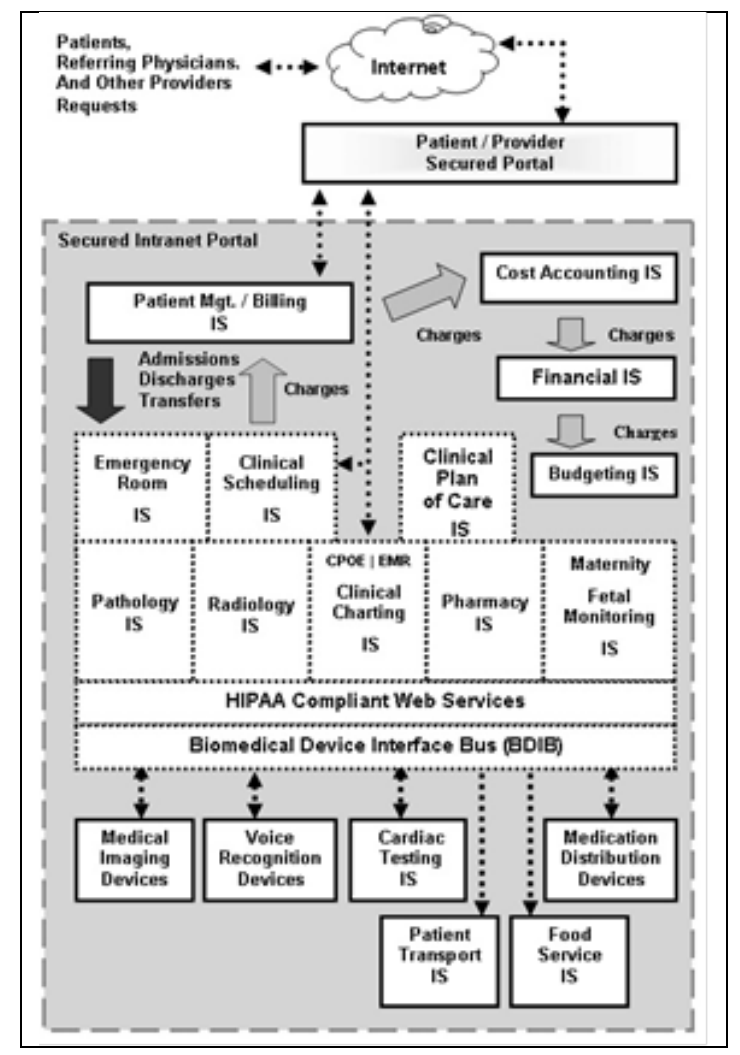

Figure-2 UHHS Integrated IS

\section{Perioperative Observed Effects}

Surgical patients move through the perioperative workflow via the following events: (1) A clinic visit resulting in scheduling a patient's surgery, (2) PACT Clinic evaluation, (3) day of surgery Admissions, (4) PreOP, (5) Intra-operative or Endoscopy, (6) PACU, (7) PACU Phase-II, and (8) discharge or movement to a medical bed. The following sections review perioperative patient care during these workflow events and the corresponding EMR documentation or facilitation via the integrated hospital IS depicted in Figure-2.

\subsection{Patient care documentation as EMRs}

UHPS developed and configured CSIS nursing records as EMRs to document and manage patient care accountability across perioperative workflow. UOS standards reflect perioperative staff work hours 
associated with particular patient care activities-one hour of patient care time, an Endoscopy procedure, or a sterilized instrument load. UOS metrics reflect patient hours in each workflow. Table-3 represents a listing of CSIS nursing documentation EMRs, year of the UOS charge capture implementation, UOS standard, and UOS unit. Prior to the implementation of each real-time UOS charge capture, perioperative staff manually batchkeyed UOS charges. As of FY2017, CSIS nursing EMRs capture UOS charge data (i.e., UOS standard multiplied by UOS units) automatically, in real-time, on completion of the surgical case and passing EMR reconciliation quality control checks.

Aggregated UOS charge data has granularity and CSIS OLAP offers contextual understanding for BPM efforts and KPI metrics. CSIS nursing EMRs differentiate patient care for charge billing and resource allocations. Within PACU, the Phase-II and intensive care units (ICU) nursing EMRs facilitate workflow and bed/resource utilization. Moreover, ICU EMRs identify capacity issues to avoid unplanned ICU discharges [45].

Table-3 - CSIS Nursing Documentation and UOS

\begin{tabular}{|l|c|c|c|}
\hline $\begin{array}{l}\text { CSIS Documentation via } \\
\text { Nursing EMRs }\end{array}$ & $\begin{array}{c}\text { FY } \\
\text { Start }\end{array}$ & $\begin{array}{c}\text { UOS } \\
\text { Std. }\end{array}$ & $\begin{array}{c}\text { UOS } \\
\text { Unit }\end{array}$ \\
\hline Ancillary Record - Family & 2007 & -- & -- \\
\hline PreOP Nursing Assessment & 2012 & 1.93 & Time \\
\hline Endo PreOP Nursing Record & 2014 & -- & Procedure \\
\hline Endo Sedation Nursing Record & 2014 & 2.1 & Time \\
\hline $\begin{array}{l}\text { PreOp Regional Block Nursing } \\
\text { Record }\end{array}$ & 2014 & 2.21 & Time \\
\hline CSS & 2003 & 3.52 & $\begin{array}{c}\text { Sterilized } \\
\text { Load }\end{array}$ \\
\hline OR Nursing Record - CVOR & 2007 & 9.04 & Time \\
\hline $\begin{array}{l}\text { OR Nursing Record - Cardiac } \\
\text { Perfusion }\end{array}$ & 2012 & 4.22 & Time \\
\hline OR Nursing Record - GENOR & 2003 & 7.45 & Time \\
\hline OR Nursing Record - ENDO & 2014 & 6.92 & Procedure \\
\hline $\begin{array}{l}\text { Ancillary Record - Room } \\
\text { Cleanup }\end{array}$ & 2005 & -- & Time \\
\hline PACU Nursing Record & 2010 & 2.71 & Time \\
\hline $\begin{array}{l}\text { ICU/After Hours PACU } \\
\text { Overflow Record }\end{array}$ & 2014 & 2.71 & Time \\
\hline $\begin{array}{l}\text { PACU Phase-II Nursing } \\
\text { Record }\end{array}$ & 2014 & 1.93 & Time \\
\hline
\end{tabular}

\subsection{Surgical case scheduling}

Surgeons, surgeons' staff, or SSS staff schedule surgical cases from their office via the CSIS in Figure-2, with synchronous scheduling of PACT Clinic evaluation appointments. In the CSIS, the surgeon or staff per surgeon's request creates a surgical case for a patient's procedure using a SPC (e.g., Table-2). Released OR suites and available openings in each SSS OR schedules are visible for selection via CSIS screens.

Posting the surgical case into the schedule queue creates an ambulatory EMR with standardized associated surgical procedure orders (i.e., Clinical Plans of Care IS) for the patient. Via the Clinical Charting IS (i.e., CPoE), the surgeon or staff can add customized orders to the EMR from available options reflected from templates configured in the Clinical Plan of Care IS. The EMR also accepts pertinent external records (i.e., medical records from outside UHHS) as attachments.

\subsection{PACT Clinic evaluation}

During the PACT evaluation, the surgeon performs a focused surgical assessment of the patient and confirms surgical consent, documenting the results into the patient's case clinic notes via the CSIS. The surgeon may also order cardiac/diagnostic testing or a cardiac/medical consultation as needed via the CPoE, which authorizes and requests the services via the corresponding ancillary IS. All test results (e.g., Stress, EKG, Imaging/Xray, or Lab) post to the patient's EMR via the BMDIB depicted in Figure-2. EMR documentation of cardiac/medical consultations occur via the Clinical Charting IS. Also during the PACT evaluation, a PreOP nurse completes the patient's PreOP Nursing Assessment Record via the CSIS. The PreOP Nursing Assessment Record documents the patient's complete preoperative medical history, physical exam, confirmation of informed surgical consent, optimized medications, and patient education.

\subsection{Day of surgery admissions}

Surgical patient admissions occur via the Patient Mgt. / Billing IS depicted in Figure-2. During Admissions, perioperative staff document family contact information via the CSIS as an Ancillary Record for Family EMR and

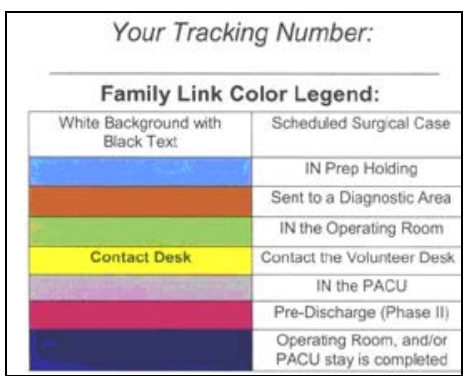

Figure-3 - Family Link legend informs family members how to view their patient's location and status. Figure-3 depicts the Family Link legend for patient status inquiries.

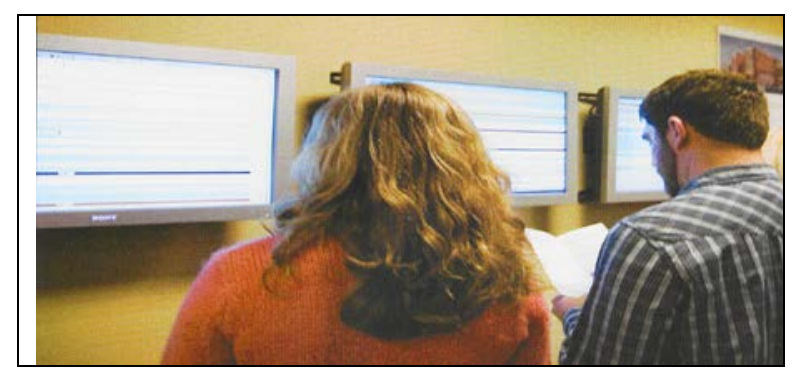

Figure-4 - Family Link Boards in OR Waiting Room

Figure 4 depicts patient status boards in an OR waiting room. After Admissions, the CSIS provides a 
HIPAA compliant visible interface to a patient's surgical case status (i.e., both outpatient and in-patient), including the in-patient's location after PACU discharge, over wall-mounted, color-coded displays throughout the PreOP, OR, PACU, and waiting areas. Via real-time clinical updates of the patient's progress in the CSIS, patient stakeholders can track patient progress and clinical staff can anticipate patient's arrival, as well as update the patient's case EMRs during the specific perioperative encounter.

\subsection{PreOP}

PreOP nurses prepare patients for their surgical procedures per surgeon/anesthesiologist orders (e.g., CPoE and Pharmacy IS depicted in Figure-2), while providing acute patient care after initial anesthesia. Within the CSIS, PreOP Nursing Assessment and Endo PreOP Nursing Record EMRs document PreOP ambulatory patient care. A Regional Block Nursing Record or Endo Sedation Nursing Record posted as EMRs to the patient's surgical case identifies when PreOP acute patient care begins. This clinical documentation identifies acute care, which incurs higher patient UOS charges. PreOP acute and ambulatory patient care EMRs capture UOS charges that flow through to the Budgeting IS as depicted in Figure-2.

\subsection{Intra-operative or Endoscopy}

Anesthesiologists', surgeons', and intra-operative staff's schedules are dynamically linked and distributed over wall-mounted monitors throughout the OR facilities via the CSIS, informing clinical stakeholders when surgical patients are scheduled, in-progress, completed, or shifted from one OR suite or scheduled time slot to another. Prior to the PreOP patient's arrival, staff setup the scheduled OR suite according to CSIS SPC specific equipment, devices, and CSS case cart. Intravenous medications (e.g., CPoE, Pharmacy IS, and medication distribution devices via Figure-2) are available as ordered or needed. The CSS prepared case cart (e.g., up to 8-hours in advance) contains supplies and instruments for the patient's specific surgical procedure per the CSIS SPC pick list (e.g., Table 1) [37].

Once the patient arrives, an OR nurse begins the OR Nursing Record (i.e., CVOR, Cardiac Perfusion, GENOR, or ENDO) data entry via the CSIS. The OR Nursing Record EMRs document all people, time, and activities while the patient is in the OR as required by TJC and CMS as well as all medication, blood, tissue, device, and supply usage. Within the CSIS, the OR Nursing Record EMRs capture UOS time and supply charges that flow through to the Patient Mgt./Billing IS and on through to the Budgeting IS (e.g., Figure-2).

Other CSIS intra-operative documentation includes quality issues for patient longitudinal outcomes, retained object counts, and robotic usage. CSIS clinical data collection also occurs via the BMDIB, as depicted in Figure-2, from sophisticated medical equipment like cardio-vascular perfusion, sensor monitors for patient's vital signs, or smart cabinets that transfer tissue transplant traceability to the patient's EMR. The final intra-operative CSIS documentation occurs after intraoperative surgical activities are completed, while the patient is in transport from the OR suite to PACU. The OR staff enters an Ancillary Record Room Cleanup EMR to document the UOS spent on the OR suite clean up and setup of the next scheduled surgical patient (i.e., data source of TAT KPI).

\subsection{PACU}

PACU nurses receive surgical patients from the OR and continue acute care per surgeon's orders until patient recovery. As a critical care unit similar to the OR suite, the CSIS collects PACU clinical data from bio-medical equipment and monitoring sensors (e.g., BMDIB in Figure-2). The PACU Nursing Record EMR documents acute care delivery. The ICU/After Hours PACU Overflow Record EMR, via the CSIS, documents acute care for patients that are over-nighting in PACU due to overflow conditions in the ICU. Both PACU acute patient care EMRs capture patient UOS charges as depicted in Figure-2.

\subsection{PACU Phase-II}

As surgical patients recover from anesthesia, the need for acute care lessens. Within the CSIS, a PACU Phase-II Nursing Record EMR posted to the patient's surgical case identifies when PACU acute care ends. PACU Phase-II Nursing Record EMRs document ambulatory care that has lower patient UOS charges and allows any UHHS hospital bed having ambulatory patient care to become PACU Phase-II. Hence, PACU Phase-II Nursing Record EMRs via the CSIS create a virtual PACU allowing more critical patients to remain in PACU acute care beds.

\subsection{Patient Discharge}

When surgical patients completely recover from anesthesia, the attending nurse discharges the patient from Phase-II and discontinues documentation to the patient's surgical case. Likewise, post-operative staff discharge outpatients per surgeon orders, while inpatients move to a hospital bed. Discharged or inpatient transportation occurs via the Patient Transport IS depicted in Figure-2.

Within two weeks of hospital discharge or a UHHS clinic visit, patients receive satisfaction surveys via email to provide feedback on their UHHS experience. The patient satisfaction data is collected, analyzed, and aggregated as a KPI metric for BPM and annual goal attainment in the UHHS strategic plan [36]. UHHS patients also have secured Internet access via the patient/provider portal (e.g., depicted in Figure-2) for 
communication with healthcare providers, health record information, upcoming appointments, or medication renewal requests.

\section{Discussion}

The previous sections on case background and observed effects demonstrate the digital transformation of UHHS' perioperative process where UHPS' BPM and CSIS integration efforts have supported a tight coupling between patient care, perioperative workflow (i.e., patient flow), and the integrated hospital IS. To this end, the data in the CSIS models the real world and reinforces data quality requirements of "fitness for use" [15]. Likewise, CSIS nursing EMRs coordinate, facilitate, document, communicate, and reflect patient level quality of care, outcomes, and, safety. Pratt et al. [31] suggests EMRs and healthcare IS fit the computer supported cooperative work (CSCW) paradigm [12] and should be viewed via a CSCW lens. Moreover, the CSIS scheduling information and nursing EMRs yield aggregated surgical case (i.e., patient) data leveraged as KPI metrics to further understand, manage, and improve perioperative workflow, resources, and performance $[36,38]$. The following sub-sections discuss digital maturity, defensive for offensive IT impact, and digital transformation CSFs with respect to the literature, case background, and observed effects.

\subsection{Digital maturity}

Strategy, culture, and employee talent reflect the level of organizational digital maturity, which is a CSF for digital transformation [21]. With respect to strategy, digital transformation requires reconfiguring business processes to exploit health IT abilities and information through a variety of digital technologies integrated across people, processes and functions. Increasing health IT impact on core capabilities (e.g., Figure-1) moves an organization from incremental improvement to business process redesign. To this end, UHPS uses CSIS data to improve perioperative sub-processes through CPI and BPR via business analytics, OLAP, and data mining (e.g., see Table 2). Likewise, having high IT impact on core strategy and increasing IT impact on core capabilities moves an organization from emerging opportunity to business transformation. The CSIS nursing EMRs are examples of implementing health IT innovatively. Furthermore, the aggregated CSIS data is the source of KPI metrics. UHHS also uses KPI targets and BPM efforts as objectives and annual goals for personnel and SSSs to meet in its strategic plan [36].

Organizational culture can enable leveraging IT for digital transformation. With UHPS' BPM approach, multi-disciplinary teams are empowered to use datadriven methodology in evaluating process variances to apply improvement or innovation. The intra-operative KPI OTS metric is an example of such evaluation. Prior to FY2012, the 70\% OTS target was elusive, in part due to incomplete PreOP documentation. As a result, the PACT Clinic inception and implementation minimized incomplete documentation with mandatory PACT evaluations to improve OTS metrics and perioperative work flow [37].

Having personnel who understand the business and can conceptualize new IT impact on current processes is necessary to leverage IT for digital transformation [21]. UHHS and UHPS administration understand IS and IT require management oversight by perioperative subject matter experts who have IT and analytical skills. Since FY2005, UHPS has consistently taken perioperative registered nurses (RNs), who understand the workflow, and trained them in health IT support as nursing educators, CSIS analysts, OR schedulers, CSS supervisors, or robotics nurses. UHPS was awarded an $\mathrm{E}^{3}$ Cardinal Health Foundation Grant in 2010 to fund an additional RN position as perioperative improvement coordinator. The position was continued and UHHS funded beyond the grant.

\subsection{Defensive for offensive IT impact}

In a digital transformation strategy, an operational backbone and a digital services platform are enterprise architecture assets essential to executing internal operational excellence (i.e., defensive IT impact) and external customer experience (i.e., offensive IT impact) [39]. The CSIS is the UHHS operational backbone providing a single source of reconciled perioperative data and 95\% of U.S. hospitals eligible for CMSEHRIP have a similar operational backbone [29]. Via the CSIS, UHPS nursing EMR charge capture provides transparent, innovative transaction processing for billing, cost accounting, financial and budgeting IS (e.g., see Figure-2). The HIPPA compliant Web services and BMDIB within the UHHS integrated IS (e.g., Figure-2) constitute a digital services platform to facilitate rapid development, implementation, and integration of digital innovations such as ancillary IS, clinical data sensors, and bio-medical equipment.

The BPM approach in managing the UHHS perioperative process via CSIS data has achieved an extraordinary level of operational excellence, as evidenced by its improved patient flow and KPI metrics [36, 37, 38]. In turn, operational excellence positions UHHS to pursue external customer experience centered on enhanced collaboration between perioperative stakeholders (e.g., healthcare providers, patients and their families). Patient status boards, patient surveys, and the patient/provider portal are examples of leveraging health IT to further extend the external customer experience by respectively providing communication, CPI feedback, and provider-patient care collaboration opportunity.

\subsection{UHPS Digital Transformation CSFs}

Digital transformation offers workflow productivity via IT applications, the ability to better manage process 
performance via data availability and visibility, as well as the ability to meet customer experience expectations [18]. UHHS was not seeking these particular benefits when it changed UHPS' governance in FY 2005, but the change evoked continuous data-driven improvement. To this end, UHPS' digital transformation has evolved over time. The following observed CSFs, summarized from the case, provide an a priori framework for UHPS' digital transformation:

The agile, integrated CSIS as an operational backbone, with the HIPPA compliant Web services and BMDIB as a digital services platform.

$\square$ CSIS implementation was phased to achieve proof of concept-first in intra-operative and CSS, moving then upstream to PreOp, then downstream to PACU, and last hospital-wide.

Accessible and visible data via the CSIS having high data quality and data integrity.

$\square$ Changed governance using matrix-style management from cross-functional departments.

$\square$ Empowered multi-disciplinary teams and integrated knowledge workers who are perioperative subject matter experts and IT literate.

$\square$ An organizational culture focused on continuous improvement using data-driven decision-making.

$\square$ A BPM approach to perioperative performance and improvement that is aligned to hospital strategy.

\section{Conclusion}

This paper fills a healthcare literature gap noted by Agarwal et al. [4] in examining the integration and use of EMRs leveraged as health IT. Furthermore, this study contributed to the healthcare IT literature by examining perioperative digital transformation through the lens of IT impact to prescribe an a priori framework to foster the occurrence. Moreover, empowered teams, integrated IS coupled to workflow, leveraged health IT, and a holistic BPM approach supported this study's observed effects in the digital transformation of a hospital's perioperative process. The observed effects demonstrated CPI and BPM as adaptable practices when leveraging health IT in the hospital environment. Likewise, the analysis, evaluation, and synthesis cycle of CPI and BPM within the observed effects demonstrated communication, innovation, as well as individual and collective organizational learning.

This study has limitations. One limitation to the study's generalization to other hospitals would be if a hospital's IS architecture lacked the digital services platform required to facilitate implementation and integration of digital innovation opportunities. The study is also limited to a single case, where future research should broaden focus as well as address other limitations inadvertently overlooked.

Overall, the study results were exploratory and need further confirmation. The case examples can serve as momentum for perioperative methodology, complexity comprehension, and improvement extension. Researchers may choose to further or expand the investigation, while practitioners may apply the practices within their perioperative environment.

\section{References}

[1] Ackoff, R. (1967). "Management misinformation systems," Management Science, 14(4), 142-156.

[2] Aiken, L., Cimiotti, J., Sloan, D., Smith, H., Flynn, L., \& Neff, D., (2011). "The effects of nurse staffing and nurse education on patient deaths in hospitals with different nurse work environments,” Medical Care, 49(12), 1042-1053.

[4] Agarwal, R., Gao, G., DesRoches, C., \& Jha, A. (2010). "Research Commentary-The Digital Transformation of Healthcare: Current Status and the Road Ahead,” Information Systems Research, 21(4), 796-809.

[5] Andai-ancion, A., Cartwright, P., \& Yip, G., (2003). "The digital transformation of traditional business," MIT Sloan Management Review, 44(4), 34 - 41.

[6] Applegate, L., McFarlan, F. \& Austin, R., (2009). Corporate Information Strategy and Management: Text and Cases. 8th ed. New York: Irwin/McGraw-Hill.

[7] Arthur, M. \& Odo, M., (2010). "The Practice of Anesthesiology and Perioperative Care," AMWA Journal, 25(2), 50-56.

[8] Bharadway, A., El Sawy, O., Pavlou, P., \& Venkatraman, N., (2013). "Digital Business Strategy: Toward a Next Generation of Insights," MIS Quarterly, 37(2), 421-482.

[9] Blumenthal, D. \& Tavenner, M., (2010). "The 'Meaningful Use' Regulation for Electronic Health Records," New England Journal of Medicine, 363(6), 501-504.

[10] Catalano, K. \& Fickenscher, K. (2007). "Emerging technologies in the OR and their effect on perioperative professionals,” AORN Journal, 86(6), 958 - 969.

[11] CMS. National Health Expenditures data. https://www .cms.gov/Research-Statistics-Data-and-Systems/Statistics-Tren ds-and-Reports/NationalHealthExpendData/NationalHealthAc countsProjected.html. Accessed June 9, 2018.

[12] Dix, A., Finlay, J., Abowd, G., \& Beale, R., (2003). Human-Computer Interaction, 3rd ed., Upper Saddle River, NJ: Prentice-Hall

[13] Eisenhardt, K., (1989). "Building theories from case study research", Academy of Mgt. Review, 14(4), 532-550.

[14] Fowler, P., Craig, J., \& Fredendall, L., (2008). "Perioperative workflow: barriers to efficiency, risks, and satisfaction,” AORN Journal, 87(1), 187-208.

[15] Gertz, M., (1998). "Managing data quality and integrity in federated databases," Proceedings of the IFIP TC11 Working Group 11.5, Second Working Conference on Integrity and Internal Control in Information Systems: Bridging Business Requirements and Research Results, 211 - 230.

[16] Herzer, K. R., Mark, L. J., Michelson, J. D., Saletnik, L. A., \& Lundquist, C. A., (2008). "Designing and implementing a comprehensive quality and patient safety management model: a paradigm for perioperative improvement," Journal of Patient Safety, 4(2), 84 - 92. 
[17] Hess, T., Matt, C., Benlian, A., \& Wiesböck, F., (2016). "Options for formulating a digital transformation strategy," MISQ Executive, 15(2), 123-139.

[18] IDG (2018). "State of digital business transformation," available online 04/16/2018 via https://www.idgconnect.com/ abstract/30222/idg-research-the-digital-business-transformatio n-landscape, accessed June 9, 2018, 9.

[19] Jeston, J. \& Nelis, J. (2008). Business Process Mgt: Practical Guidelines to Successful Implementations, 2nd ed. Burlington, MA: Elsevier, Ltd.

[21] Kane, G., Palmer, D., Phillips, A., \& Kiron, D., (2015). "Is your business ready for a digital future?," MIT Sloan Management Review, 56(4), 37-44.

[22] Kanich, D. G. \& Byrd, J. R., (1996). "How to increase efficiency in the operating room," Surgical Clinics of North America, 76(1), 161 - 173

[23] Macario, A., Vitez, T., Dunn, B., \& McDonald, T., (1995). "Analysis of hospital costs and charges for inpatient surgical care,” Anesthesiology, (83)6, 1138 - 1144.

[24] Matt, C., Hess, T., \& Benlian, A., (2015). "Digital transformation strategies,” Bus Inf Syst Eng, 57(5), 339-343.

[25] Marjamaa, R., Vakkuri, A., \& Kirvela, O., (2008). "Operating room management: why, how and by whom?," Acta Anaesthesiol Scandanavia, 52(5), 596-600.

[26] McClusker, J., Dendukuri, N., Cardinal, L., Katofsky, L., \& Riccardi, M. (2005). "Assessment of the work environment of multidisciplinary hospital staff," International Journal of Health Care Quality Assurance, (18)7, 543 - 551.

[27] Morakanyane, R., Grace, A., \& O’Reilly, P., (2017). "Conceptualizing digital transformation in business organizations: A systematic review of the literature," BLED 2017 Proceedings, 21.

[28] Munroe, M., \& Wheeler, B., (1980). "Planning, critical success factors, and management's information requirements," MIS Quarterly, 4(4), 27 - 37.

[29] ONC (2017). "Hospital progress to meaningful use," available online 08/01/2017 via dashboard.healthit.gov/ quickstats/pages/FIG-Hospital-Progress-to-Meaningful-Useby-size-practice-setting-area-type.php. Accessed June 9, 2018.

[30] Peters, J. \& Blasco, T. (2004). "Enhancing hospital performance through perioperative services," Physician Executive, 30(6), 26 - 31.

[31] Pratt, W., Madu, C., McDonald, D., Tarcy-Hornoch, P., \& Gennari, J., (2004). "Incorporating ideas from computersupported cooperative work", Journal of Biomedical Informatics, 37, 128-137.

[32] PwC Health Research Institute (2012). "The future of the academic medical center: strategies to avoid a meltdown," PricewaterhouseCoopers $L L P$, available online 2/01/2013 via http://www.pwc.com/us/en/health-industries/publications/thefuture-of-academic-medical-centers.jhtml\#, accessed 05/25/2018, 44

[33] Rockart, J., (1979). "Chief executives define their own data needs,” Harvard Business Review, 57(2), 81- 93.

[34] Rothschild, J. (2004). "Computerized physician order entry in the critical care and general inpatient setting: a narrative review," Journal of Critical Care, 19(4), 271-278.
[35] Ryan, J., Doster, B., Daily, S., \& Heslin, M., (2008). "Soft Innovation as Data-Driven Process Improvement Exploited via Integrated Hospital Information Systems," Proceedings of the 41st Hawaii International Conference on System Sciences, Computer Society Press, 10.

[36] Ryan, J., Doster, B., Daily, S., \& Lewis, C., (2014). "A balanced perspective to perioperative process management aligned to hospital strategy," International Journal of Healthcare Information Systems \& Informatics (IJHISI) (9:4), 1-19.

[37] Ryan, J., Doster, B., Daily, S., \& Lewis, C., (2016). "A case study perspective for balanced perioperative workflow achievement through data-driven process improvement," IJHISI (11:3), 19-41.

[38] Ryan, J., Doster, B., Daily, S., \& Lewis, C., (2017). "Using key performance indicators to reduce perceived complexity \& improve patient workflow," IJHSI (12:4), 13-30.

[39] Sebastian, I., Mocker, M., Ross, J., Moloney, K., Beath, C., \& Fonstad, N., (2017). "How big old companies navigate digital transformation,” MISQ Executive, 16(3), 197-213.

[40] Schadler, T., \& Fenwick, N., (2017). "The digital business imperative," Forrester, available online 2/15/2017 via https://www.forrester.com/report/The+Digital+Business+Impe rative/-/E-RES115784, accessed June 9, 2018.

[41] Silverman, D. \& Rosenbaum, S., (2009). "Integrated assessment and consultation for the preoperative patient," Medical Clinics of North America, 93, 963-977.

[42] Tenner, A.R., \& DeToro, I.J., (1997). Process redesign: the implementation guide for managers. Upper Saddle River, NJ: Prentice-Hall, Inc.

[43] Tarantino, D., (2003). "Process Redesign Part 1: Process Selection,” The Physician Executive, 29(6), 71-73.

[44] Turban, E.; Sharda, R.; Aronson, J.; \& King, D. (2008). Business Intelligence: A managerial approach. Upper Saddle River, New Jersey: Prentice Hall

[45] Utzolino, S., Kaffarnik, M., Keck, T., Berlet, M., \& Hopt, U., (2010), "Unplanned discharges from a surgical intensive care unit: readmissions and mortality," Journal of Critical Care, 25, 375-381.

[46] Walton, M., (1986). The Deming Management Method. New York: Dodd, Mead.

[47] Weber, R., (2004). "The rhetoric of positivism versus interpretivism: a personal view,” MIS Quarterly, 28(1): iii-xii.

[48] Wears, R. \& Berg, M., (2005). "Computer technology and clinical work: still waiting for Godot", JAMA, 293(10), 1261-1263.

[49] Wright, J., Roche, A., \& Khoury, A., (2010). "Improving on-time surgical starts in an operating room," Canadian Journal of Surgery, 53(3), 167-170.

[50] Yin, R. K., (2003). Case study research: Design and methods, Third Edition. Thousand Oaks, California: Sage.

[51] Zani, W. M. (1970). "Blueprint for MIS," Harvard Business Review, 48(6), 85 - 90. 